\title{
THE ECONOMIC AND SOCIAL IMPACTS OF WATER SCARCITY IN THE IR IRAN
}

\author{
Scott VITKOVIC ${ }^{1^{*}}$ and Daryoush SOLEIMANI ${ }^{2}$ \\ ${ }^{1}$ Howzeh Elmiyeh, Qom, Islamic Republic of Iran, p29.12.1392@gmail.com \\ ${ }^{*}$ Corresponding Author
}

\begin{abstract}
The past 15 years of exceptionally severe water scarcity in the Islamic Republic of Iran have resulted in the desertification and salinity of formerly arable lands, drying out of Iranian lakes and rivers, and quickly shrinking groundwater resources, while water demand has risen, along with the size of the Iranian population, of which over $70 \%$ lives in urban areas now. We have aimed to discover the causes of water scarcity in the IR Iran and evaluated its social and economic impacts. First, we computed the Weighted Anomaly Standardized Precipitation (WASP) Index for the period of 1979-2014. To illustrate the social impact of water scarcity, we analyzed the current water risk for the twenty most populous Iranian cities, by employing the composite index approach to translate hydrological data into comprehensible indicators of water related risks, and made a projection for 2020-2030, by modeling potential changes in the future demand and supply of water. To demonstrate the economic impact of water scarcity, we evaluated the overall agricultural contribution to the IR Iran GDP. We have found that the 1999 severe drought in the IR Iran commenced a period of unusually dry conditions that is still ongoing. The rapidly growing Iranian urban populations presently experience a medium to extremely high overall water risk, with extremely high baseline water stress that, in part, is due to the lack of upstream protected lands. The relationship between baseline water stress and drought severity has been determined as weak, confirming that other factors than drought are equally or more important contributors to the existing water risk. Our projection calculations indicate that Iranian urban populations will continue to experience an extremely high water stress for the coming decade. Due to the fast growth of these populations as well as considerable rise of value added to the IR Iran GDP by other sectors of the national economy, the contribution of agricultural production to the national GDP has declined from about $25 \%$ to under $10 \%$ (although its total yield has risen considerably) during the past 30 years. This decrease has been directly proportional to the increased foreign food imports, dependency on the IR Iran oil exports and reduction in the non-oil exports. The main causes of water scarcity in the IR Iran appear to be due to climatic factors, insufficient environmental protection, and over-exploitation and mismanagement of water resources, especially by the agricultural sector. In conclusion, our study proposes anti-wasting water management action plan that recommends shifting the IR Iran government response to water scarcity from reactive survival strategies to proactive crisis prevention, with emphasis on safeguarding, monitoring, early warning, and effective step-by-step preparedness and readiness, and by laterally integrating water management between all levels of the IR Iran government, including local, regional and national, for a sustainable, resilient and prosperous economy of the Islamic Republic of Iran now and in the future.
\end{abstract}

Keywords: Agriculture, Desertification, Drought, Environment, GDP, Islamic Republic of Iran, Pollution, Salinity, Urbanization, Water, Weighted Anomaly Standardized Precipitation (WASP) Index; 


\section{INTRODUCTION \& LITERATURE REVIEW}

\subsection{Water Scarcity in the Islamic Republic of Iran}

Water scarcity is the lack of sufficient available water resources to meet the demands of water usage within a region. Water scarcity involves (Figure 1 ):

Water stress denotes the difficulty of obtaining sources of fresh water for use during a period of time and may result in further depletion and deterioration of available water resources.

Water shortage may be caused by climate change, such as altered weather patterns, including droughts or floods, growing environmental pollution, and increased human demand for existing water resources.

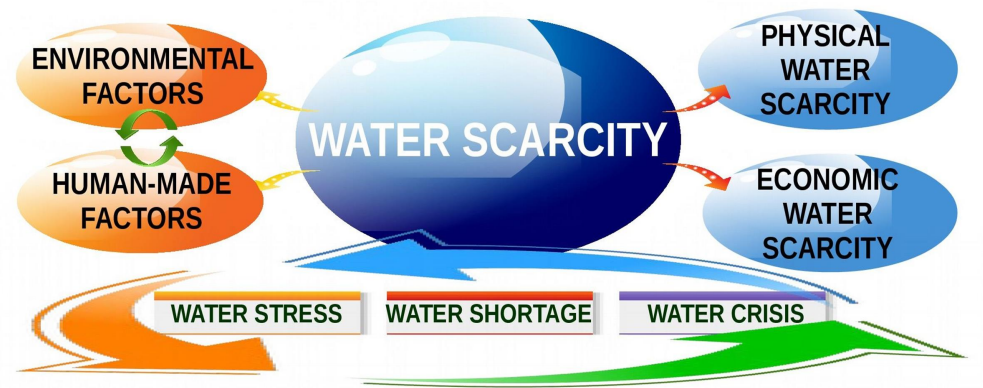

FIGURE 1: Water Scarcity Diagram, Source: Own Diagram, 2015;

Water crisis is a situation where the available unpolluted water within a region is less than that region's demand.

\section{Causes \& Manifestations of Water Crisis}

Inadequate access to safe drinking water; Excessive and wasteful use of ground water; Inadequate access to sanitation leading to waterborne diseases; Pollution of the environment; Water scarcity is both a natural and a human-made phenomenon. The Earth has more than enough freshwater on to sustain seven billion people, but the water resources distribution is uneven and much water is wasted, polluted and mismanaged.

Economic Water Scarcity is a consequence of poor management of the available water resources. It is more often found to be the predominant cause of water scarcity, as most countries have enough water to meet household, industrial, agricultural, and environmental needs, but lack the means to provide it in an accessible and efficient manner. Approximately 1.6 billion people, or almost one quarter of the world's population, face economic water shortage (United Nations Development Programme, 2006).

Physical Water Scarcity is a consequence of inadequate natural water resources to supply a region's demand. Symptoms of physical water scarcity include environmental degradation and declining groundwater as well as other forms of exploitation. Critical conditions often arise for economically poor and isolated communities living in already dry environment. Around 1.2 billion people, or almost one-fifth of the world's population, live in areas of physical scarcity, and 500 million people are approaching this situation (United Nations Development Programme, 2006).

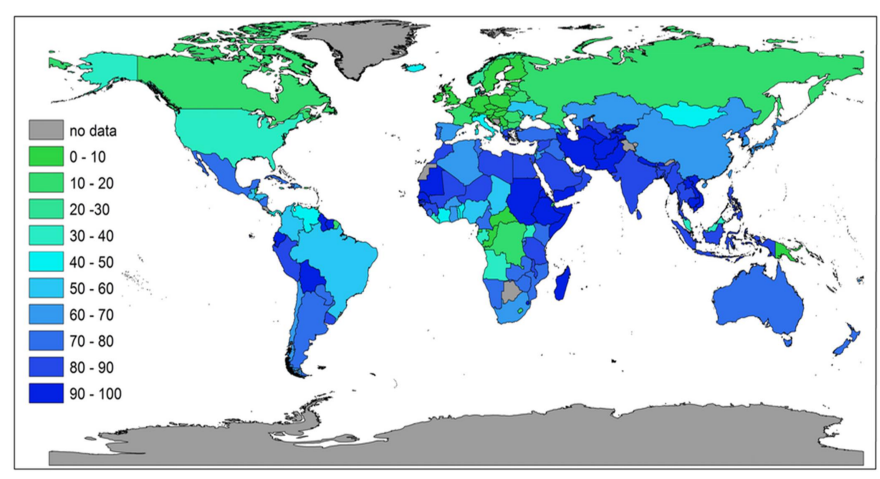

FIGURE 2: Annual total fresh water withdrawals in agriculture per country [\%] in 2012, Data: World Bank Water scarcity has many negative impacts on the economy, society and the environment, including the lakes, rivers, wetlands, and other fresh water resources. The resulting water overuse, that is related to water scarcity, often located in areas of irrigation agriculture, harms the environment by increased salinity, pollution, 
the loss of wetlands and desertification of arable lands (United Nations Development Programme 2006). The effective and sustainable use of water for agriculture has become a global priority of vital importance, requiring an urgent solution (Akbari et al. 2009).

\subsubsection{Environmental Factors:}

\section{- Climate}

Located in one of the most arid regions in the world (Lehane 2014, Akbari et al. 2009 and Dastorani et al. 2011), that frequently suffer from physical water scarcity, the long-term mean annual rainfall for arid and semi-arid regions in Iran is $141.1 \mathrm{~mm}$ (Modarres and da Silva 2007). Temporal and spatial rainfall distribution is variable and non-uniform; Only $10 \%$ of rainfall occurring during hot and dry seasons in central, southern and eastern spheres of the country (Garshasbi 2014), with mean rainfall (data ending in 2000) at selected stations in desertified provinces ranges from as low as $86 \mathrm{~mm}$ in Yazd province up to $271 \mathrm{~mm}$ in Khorasan Razavi province, with most recording dry years after 1999 (Figure 8). It is unclear whether these post 1999 rainfalls represent a run of very dry years or the commencement of predicted rainfall decline with climate change (Amiraslani et al. 2011). In addition, rainfall in Iran is highly seasonal, with a rainy season between October and March, leaving the land to dry during the remaining months of the year.

\section{FIGURE 3: Esfahan Zayanderood Before Esfahan Zayanderood Now}

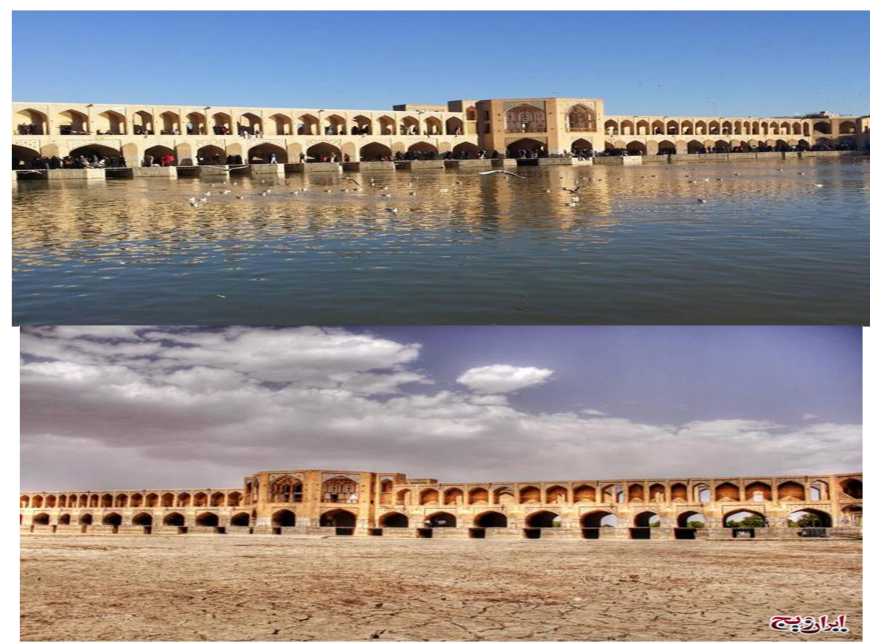

The past 15 years of exceptionally high temperatures and severe droughts in the IR Iran involved persistent deficits in precipitation (Karami et al. 2013). For example, on 31 July 2015, a temperature reaching

$73^{\circ} \mathrm{C}(163 \mathrm{~F})$ has been recorded in the Iranian port city Bandar Mahshahr, one of the hottest registered across the world to date, according to experts. The heat had been brought about by a combination of an actual temperature of $115 \mathrm{~F}\left(46^{\circ} \mathrm{C}\right)$ and a dew point temperature of $90 \mathrm{~F}\left(32^{\circ} \mathrm{C}\right)$. Faced with a critical shortage of water, the IR Iran has called for water conservation. Due to the effects of protracted droughts and desertification of formerly arable lands, Iranian lakes, rivers and groundwater resources have shrunk (Figure 3 ), while water demand has risen, along with the size of the Iranian population (Figure 6) which currently numbers about 79.5 million total, with about 55.5 million living in urban areas, and about 14.5 million in the wider metropolitan area of Tehran. The looming water crisis presents a formidable challenge.

Exacerbating the severity of water shortages, as much as $70 \%$ of precipitation is lost to evaporation (Lehane 2014). Estimates suggest that lower-than-average precipitation in 2013 caused a 30\% reduction in the volume of water in dams across the country, with only five exceeding 90 per cent capacity. According to the Institute for Forest and Pasture Research, groundwater levels have dropped two meters in recent years across 70 plains, affecting as much as 100 million hectares. Over the longer term, there are signs of more frequent and more severe droughts to come, due to global climate change, population growth, and increased water resource demands from all sectors; agriculture, industries, and municipal uses (Salami at al. 2009). According to the UN Development Program, the level of Iran's per capita water resources are predicted to fall to as little as $816 \mathrm{~m}^{3}$ in 2025, down from 2,025 $\mathrm{m}^{3}$ in 1990.

Drought has become an insidious, slow-onset natural hazard that produced a complex web of impacts (Akbari et al. 2009, Hayati et al. 2010 and Dastorani et al. 2011), rippling through many sectors of the economy, primarily the agricultural sector (Hayes et al. 2007, Hayati et al. 2010 and Karami et al. 2013). Agricultural drought has been and continues to impact food security and cropland resources (Hayati et al. 2010, Li et al. 
2014 and Bayad et al. 2015). A severe drought, such as the one that occurred in the crop year 1999-2000 (Dastorani et al. 2011), imposed a direct cost of US\$ 1.7 billion (the 2000 exchange rate was 8000 Ir Rials to one USD). This is the equivalent to $30.3 \%$ of the total value added of the cropping sector in Iran. This, in turn, led to a $12.7 \%$ reduction in the value added of other agricultural sub-sectors, such as livestock, fisheries and forestry. In the rest of the economy, the manufacturing and service sectors experienced value added declines of 7.8 and $3.7 \%$, respectively. In addition, there was a substantial decrease in investment in the agricultural, manufacturing and service sectors. Thus, such a drought reduced overall GDP by about $4.4 \%$, and also resulted in decreased non-oil exports, increased food imports, and a rise in inflation. In over $70 \%$ of rural areas, the flow of water was moderately to severely disrupt.

It is estimated that one millimeter of rainfall creates a value of USD 14.5 million in the IR Iran. In other words, a $1 \%$ decrease in precipitation below the long-run average results in a $0.68 \%$ decline in the value added of the crops and horticulture sector. Additionally, almost $80 \%$ of drinking-water wells suffered from low water yield due to a drop in the water table, and became brackish. Water reserves in July 2001 were down by $45 \%$. Some 37 million people (about $50 \%$ of Iran's total population) experienced adverse health conditions, such as skin and eye infections. The number of animals infected with internal and external parasites had important implications for productivity in the agricultural sector. According to the World Disaster Report (Walter 2004), drought and famine have proven to be the deadliest disasters worldwide (Akbari et al. 2009 and Dastorani et al. 2011). Therefore, such findings call for an urgent attention to water management in the agricultural sector of the IR Iran (Salami at al. 2009).

\section{- Geography and Geology}

Iran has one of the earliest agricultural records going back to $4000 \mathrm{BC}$. However, soil erosion and desiccation of many water sources gradually changed Iran into a dry and drought-prone land that now belongs to the arid or semi-arid zone of Asia (Foghi 2003). Over $84 \%$ of the country is arid or semi-arid, over $50 \%$ either desert or mountain, and $16 \%$ has an elevation of $2000 \mathrm{~m}$ or more above sea level. Streams are seasonal; flooding is common during the spring and dry-out during summer, leading to considerable variability in freshwater access for those reliant on surface water resources. Due to high evaporation of surface water, Iranian's have, for centuries, used traditional methods of water transport and access to supply their freshwater resources. More than 2000 years old, the karez [qanat] (Figure 4) is still used in Iran today. However, the number of karez has been greatly reduced due to the current ground water overdraft and depletion.
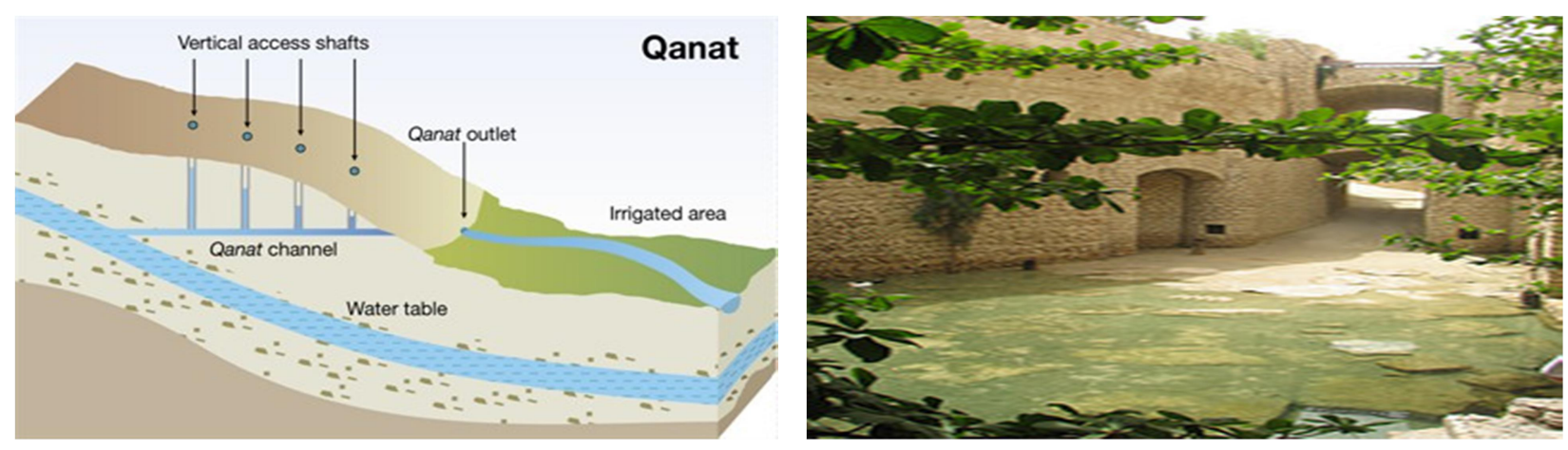

FIGURE 4: Karez Cross-section Karez

Karez has been designed to access and transfer groundwater without the use of lifting devices. Wells are sunk every 20 to 50 meters along the system, with a tunnel then built to link the wells on a slope from higher ground. Groundwater flows naturally down the tunnel till it reaches a surface point at the end, either in a town or city, or by creating an artificial desert oasis (Lehane 2014).

Iran is divided into six key and 31 secondary catchment areas. Besides the Persian Gulf and Gulf of Oman Basins, all of Iran's basins are located in the interior, where renewable freshwater sources are limited. Close to half of Iran's total renewable water is located in the Persian Gulf and Gulf of Oman Basins, representing one quarter of its land mass. Conversely, the Markazi Basin covers more than half of Iran's land mass, but holds less than one-third of the available freshwater. As of 2014 , Iran is using $70 \%$ of its total renewable freshwater, far above the upper limit of $40 \%$ recommended according to international norms.

\subsubsection{Human-made Factors}


The Islamic Republic of Iran is vulnerable to desertification due to extensive areas of dry lands and increasing population pressure on land and water resources. Iran's Bureau of Desert Affairs has identified the following provinces as having "desertified areas": Bushehr, Fars, Hormozgan, Ilam, Isfahan, Kerman, Khorasan Jonoobi, Khorasan Razavi, Khorasan Shomali, Khuzestan, Markazi, Qazvin, Qom, Semnan, Sistan-Baloochestan, Tehran and Yazd. These provinces are home to about $70 \%$ of the total Iranian population (Amiraslani et al. 2011). Primarily, the degradation of topsoil in agricultural lands has resulted in desertification. Another form of desertification is the encroachment by mobile sand dunes onto productive agricultural areas, communities, oases and even roads and rivers (Ahmad et al. 1987). Also, dust storms are a historic phenomenon in Iran and contributor to desertification, by stripping agricultural soil. Such storms are a problem especially in the eastern provinces of Iran which are most affected by water shortages and frequent droughts. The main causes of desertification in Iran are climatic factors, urbanization, overexploitation of water resources, deforestation and over-grazing (Akbari et al. 2009 and NAP 2005). These factors often interact in contributing to desertification; Adverse climatic conditions may prevent the continuation of previously sustainable levels of water use, leading to over-exploitation of the resource; and secondary land salinity may develop in association with irrigation (Qadir et al. 2008).

FIGURE 5: Lake Urmia in 1975 and Today

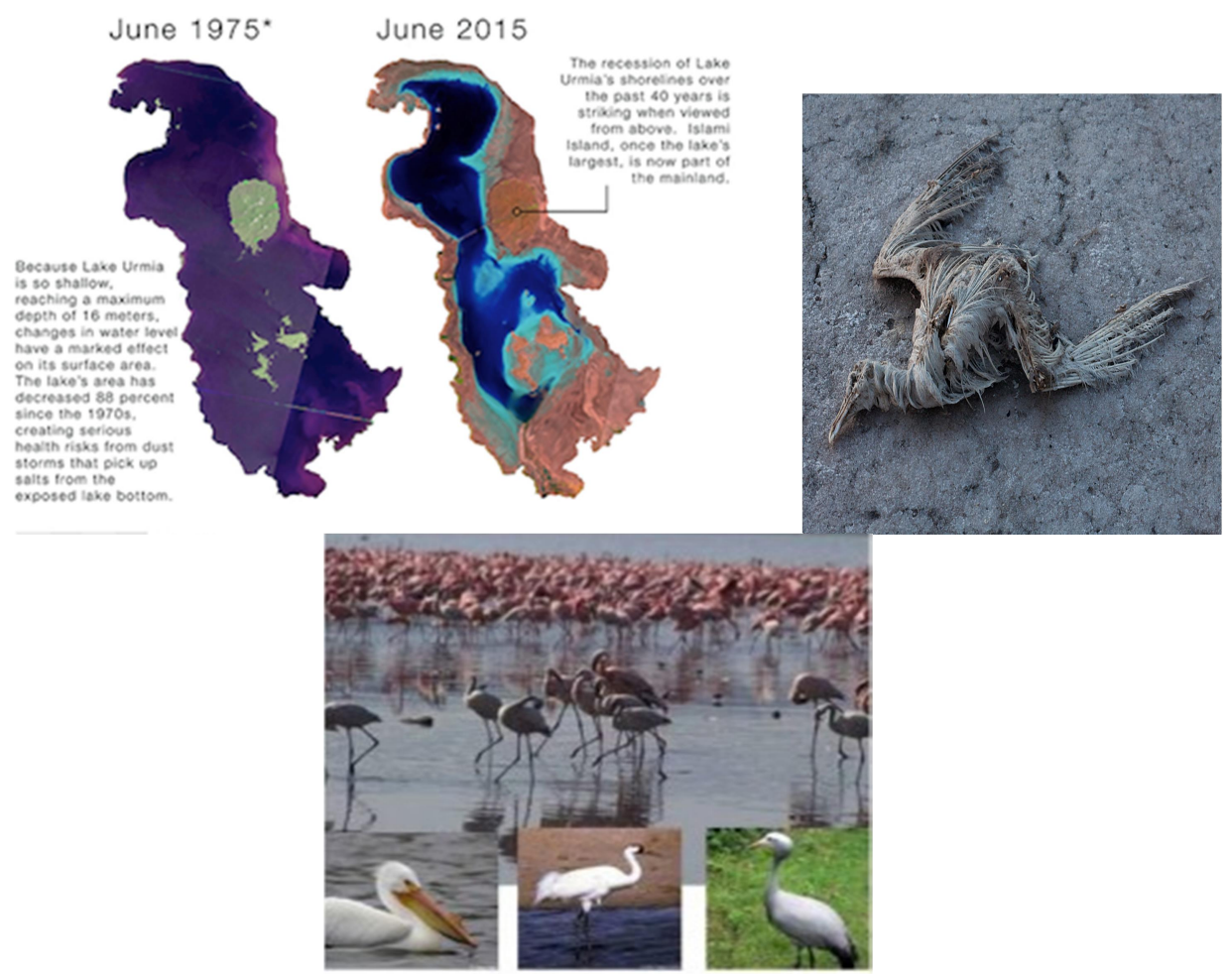

In recent years, the IR Iran has experienced serious environmental damages, including the drying-up of seasonal rivers, death of shrubs in plantations, decline in underground water resources, degradation of farmlands, urban and rural drinking water shortages, and desiccation of internationally recognized wetlands (National Report 2003). For example, the traditionally fertile Hamoun wetlands on the IR Iran's border with Afghanistan, the landscape setting for the Shahnameh, that supported an advanced ancient culture, has been reduced to a dust-covered area of $5,660 \mathrm{sq} \mathrm{km}$. For the past fifteen years, dotted with abandoned boats, the local population that for centuries lived on fishing, cattle breeding and hunting has no source of income. Poverty became widespread. Thousands, who have farmed and fished for generations, migrated to cities, as their livelihoods have literally dried up (Bozorgmehr 2015). Furthermore, three of Iran's lakes, Lake Maharlu, Lake Bakhtegan and Lake Parishan, have dried out, turned to deserts and suffered irreversible ecosystem destruction, according to the Habitats Office of the National Department of Environment. Lake Urmia (Figure 5) is also following similar path, with a 94 per cent surface water reduction, from 36 billion cubic meters to 2 billion cubic meters. Water loss in Lake Urmia has led to increased salinity, which has affected the survival of fish species and habitat. The lake is the largest in the Middle East and the third largest saltwater lake in the world, according to NASA. More importantly, if Lake Urmia dries out completely, enormous amounts of salt are about to spread over large areas of arable land, making it infertile. To save the Lake and the surrounding environment, the IR Iran is planning to discharge about 60 to 80 cubic meters per second of water into the Lake from Armenia's Lake Sevan and Georgia's Kura River via three pumping 
stations in Iran. Obtaining water from the Caspian Sea is not feasible due to the distance and water pollution.

- Urbanization

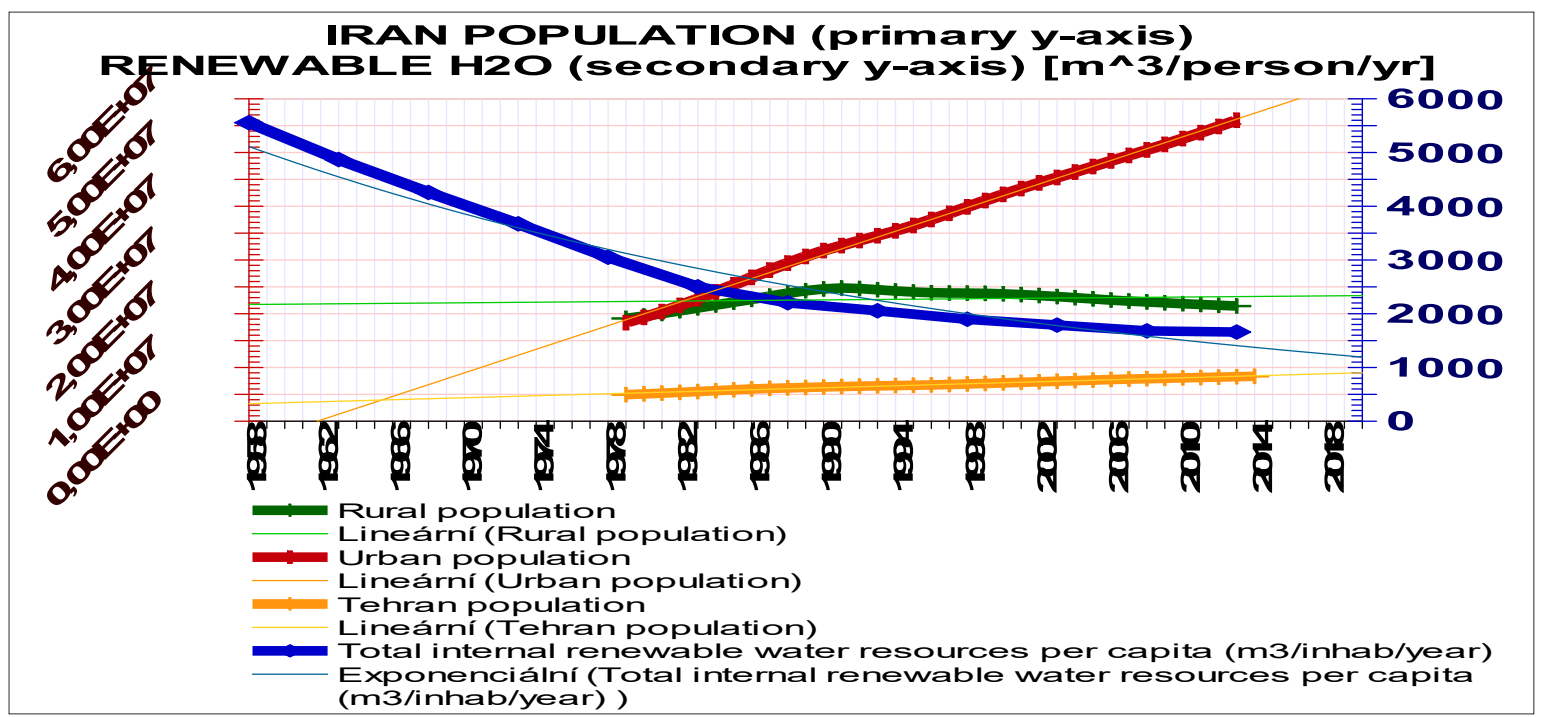

FIGURE 6: Iran: Urban, Rural and Tehran Populations (1979-2013) and Renewable Water Resources (19582013) Major demographic changes have occurred in the country since the 1920's when total population was about 10 million, and over $80 \%$ of Iranians lived in rural areas. By this year, 2015, the population is reaching about 80 million, with only about $30 \%$ of Iranians living in rural areas (Figure 6). It is estimated that Iranian population will reach over 100 million by 2060. According to the United Nations, Iran also exhibits one of the steepest urban growth rates in the world. These demographic shifts, together with economic, social and developmental changes have created a situation in which more pressure is being exerted on natural resources, namely water, soil and vegetation. These effects are felt in relation to livestock raising on farmlands, as well as in agricultural areas with their associated infrastructure (Amiraslani et al. 2011).

Furthermore, severe droughts and water scarcity in Iran have led to the evacuation of many villages (Karami et al. 2013). Migration of agricultural workers from rural areas has reduced rural development and increased social and economic problems in the cities across the IR Iran (Mahdi et al. 2014). One of the major problems is not only the reduction of locally grown food but also the imports of cheap and poor quality foodstuffs from India and China that negatively impacts both the Iranian economy and public health. Internal displacement continues to rise as climate change and prolonged droughts, and consequently the lack of jobs and poverty, exacerbate this situation.

\section{- Agriculture}

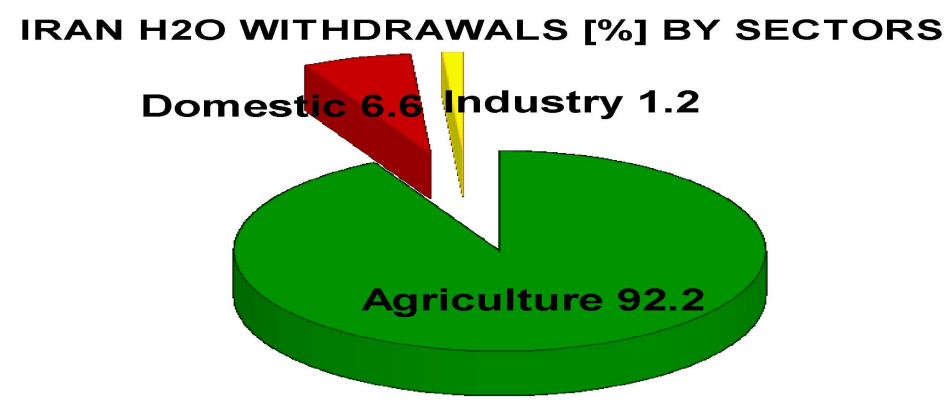

FIGURE 7: IR Iran Water Withdrawal [\%] by Sector, Source of Data: AQUASTAT

A total value added to the IR Iran GDP from Agriculture has declined in many parts of the IR Iran due to increasing water stress, arising partly from increasing temperatures and reductions in the number of rainy days (Bates et al. 2008). Agriculture is also the biggest consumer of water in Iran but has a low water use efficiency of about $30 \%$. The gravity system method of irrigation wastes about $70 \%$ of water due to evaporation and seepage (Foghi 2003, and Karimkoshteh and Haghiri 2004). Inefficient water deliveries through unlined canals allow water to be evaporated and lead to salinity of the adjacent soil.

The biggest problem of all is the massive inefficiency inside Iran's agricultural sector, which uses more than $92 \%$ of the country's total water supplies (Aliabadi et al. 2015). Indeed, irrigated agriculture (8.7 million ha) 
accounts for more than $92 \%$ of the total surface (Islamic Republic News Agency) and groundwater withdrawal and more than $60 \%$ of total renewable water resources (Faramarzi et al. 2009), (Figure 7). Water exploitation for agricultural expansion has increased due to the availability of electric pumps. A major decline in water table levels has followed, placing the water status of plains areas in particular in a critical state (Khajeddin 2007).

Cold water fish production has been also affected by the water scarcity through increased water salinity and decreased water flow rates in streams and rivers providing water to fish farms. Lower river discharges into the sea reduce the spawning of shrimps which in turn results in lower shrimp catches (Foghi 2003).

\section{- Pollution}

Cultivation of crops has intensified and led to increased fertilizer and pesticide use. Water pollution is caused by industrial and municipal waste water, as well as by agriculture. Treated waste water is used in agriculture, but in some towns, albeit in a limited form, raw waste water is used directly for irrigation, becoming a source of pollution to groundwater and a risk to public health (Mahmoodian 2001). In cities without sanitary sewerage, households discharge their sewage through open rainwater drains. Also, increased fertilizer and pesticide use is a contributing factor (The World Bank 2005). According to Mansour Ghotbi Sarabi, water expert in the Ministry of Agricultural Jihad, about $75 \%$ of the country's drinking water is derived from underground resources. However, these underground waters are subject to heavy pollution by agricultural, industrial, medical (hospital) and residential waste water (Khajehpour 2014).

\section{- Regional Mismanagement}

While water is the underlying tenuous balance of safe water supply, controllable factors such as the management and distribution of the water supply itself contribute to further scarcity. Lack of proper planning and ecological assessment has been a major problem in anti-desertification efforts in Iran (Anon 2008). Water insufficiency is mainly due to mismanagement (Foghi 2003), lack of appropriate institutions, and shortage of investment in both human capacity and physical infrastructure. In the Islamic Republic of Iran, groundwater is free to all, with no price charged even for irrigation that accounts for over $90 \%$ of water withdrawals. Yet, a large part of the water used in agriculture is evaporated, instead of properly used, because of inefficient consumption patterns. Additionally, government subsidies have greatly reduced energy costs and made groundwater extraction cheap. Irrigation has rapidly expanded beyond the capacity of traditional water systems. Therefore, dams were rapidly constructed, to keep up with the increased water demand, causing water tables to fall significantly in irrigated areas across Iran. Exploitation of water became prevalent and most of it has taken place in the central basins where less surface water is available. As ground water tables dropped, salt-water intruded into the irrigation water, further enhancing the salinity of the soil. The desertification and salinity of the land became a common phenomenon in today's Iran. Hamid Chitchian, head of the IR Iran Ministry of Energy, who also is in charge of regulating the water sector, said that, the [water] situation had reached critical levels. Chitchian correctly established that past approaches, which mainly focused on constructing dams and trying to increase the storage capacity, would no longer be appropriate remedies. In fact, total storage capacity behind the country's many dams amounts to 68 billion cubic meters, whereas the water potential of the country's rivers totals 46 billion cubic meters per annum (Khajehpour 2014).

\subsection{The Purpose of Our Research}

We aimed to discover the primary cause of water scarcity in the Islamic Republic of Iran in the past fifteen years, analyze the current water risk for the IR Iran Cities with populations greater than $300 \mathrm{~K}$, make a projection for 2020-2030, and evaluate the negative impact of water scarcity on the economy of the Islamic Republic of Iran. While there have been many scientific inquiries into the economic, social and environmental impacts of water scarcity in various regions of the world, especially in the African continents, the studies concerning the IR Iran have been limited. The original contribution of our scientific study consists in the proposal for the implementation of a concrete anti-wasting water management action plan, by shifting the IR Iran government response to water scarcity from a passive crisis management to active crisis prevention, with emphasis on safeguarding, monitoring, early warning, and effective step-by-step preparedness and readiness and by integrating water management between all levels of the government, including local, regional and national, for a sustainable, resilient and prosperous economy of the Islamic Republic of Iran.

\section{METHODS}

\subsection{Weighted Anomaly Standardized Precipitation (WASP) Index for the IR Iran (1979-2014)}

To compute the WASP Index, monthly precipitation departures from the long-term average (in this case from 1981 to 2010) were obtained and standardized, by dividing by the standard deviation of monthly 
precipitation. The standardized monthly anomalies were weighted, by multiplying by the fraction of the average annual precipitation for the given month. These weighted anomalies were then summed over threemonths periods. On the map the value of the given WASP Index has itself been standardized.

\section{2 (A) The Current Overall Water Risk for the IR Iran Cities with Populations Greater than $300 \mathrm{~K}$}

We employed the composite index approach to translate hydrological data into comprehensible indicators of water related risks. We grouped twelve indicators into a framework identifying spatial variation in water risks. For six of the twelve indicators, we used time series estimators, spatial regression, and a sparse hydrological model to generate novel data sets of water supply and use. We adapted the remaining six indicators from existing publications. We allowed for dynamic weighting to reflect the specific factors concerning the Islamic Republic of Iran to water-related risks.

\section{2 (B) The Projection of Water Risk for the IR Iran Cities with Populations $>300 \mathrm{~K}$ from 2020-30}

This analysis models potential changes in the future demand and supply of water for the IR Iran cities with populations greater than $300 \mathrm{~K}$. We estimated indicators of water demand (withdrawal and consumptive use), water supply, water stress (the ratio of water withdrawal to supply), and inter-annual (seasonal) variability for the period between 2020 and 2030 for each of two climate scenarios, RCP4.5 and RCP8.5, and two shared socioeconomic pathways, SSP2 and SSP3. We derived estimates from general circulation models (GCMs) from the Coupled Model Inter-comparison Project Phase 5 (CMIP5) and mixed-effects regression models based on projected socioeconomic variables from the International Institute for Applied Systems Analysis (IIASA)'s Shared Socioeconomic Pathways (SSP) database.

\section{RESULTS}

The following maps (Figure 8) show the "Weighted Anomaly Standardized Precipitation" (WASP) Index for the Islamic Republic of Iran from 1979 to 2014, annually. The WASP index gives a standardized measure of precipitation excesses or deficits over the measured accumulation period, and is based solely on monthly precipitation data. For the WASP Index, shading starts at $+/-1.0$, with green shades indicating unusually wet conditions and brown unusually dry, respectively. Regions with an annual average precipitation of less than $0.2 \mathrm{~mm} /$ day are not shown in the plot. The map confirms the 1999 major drought in the IR Iran. This drought commenced a period of unusually dry conditions, reflected here, which is still ongoing.

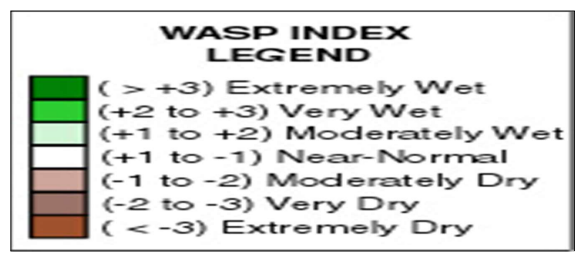

FIGURE 8: I. Weighted Anomaly Standardized Precipitation (WASP) Index for the IR Iran from 1979 to 2014

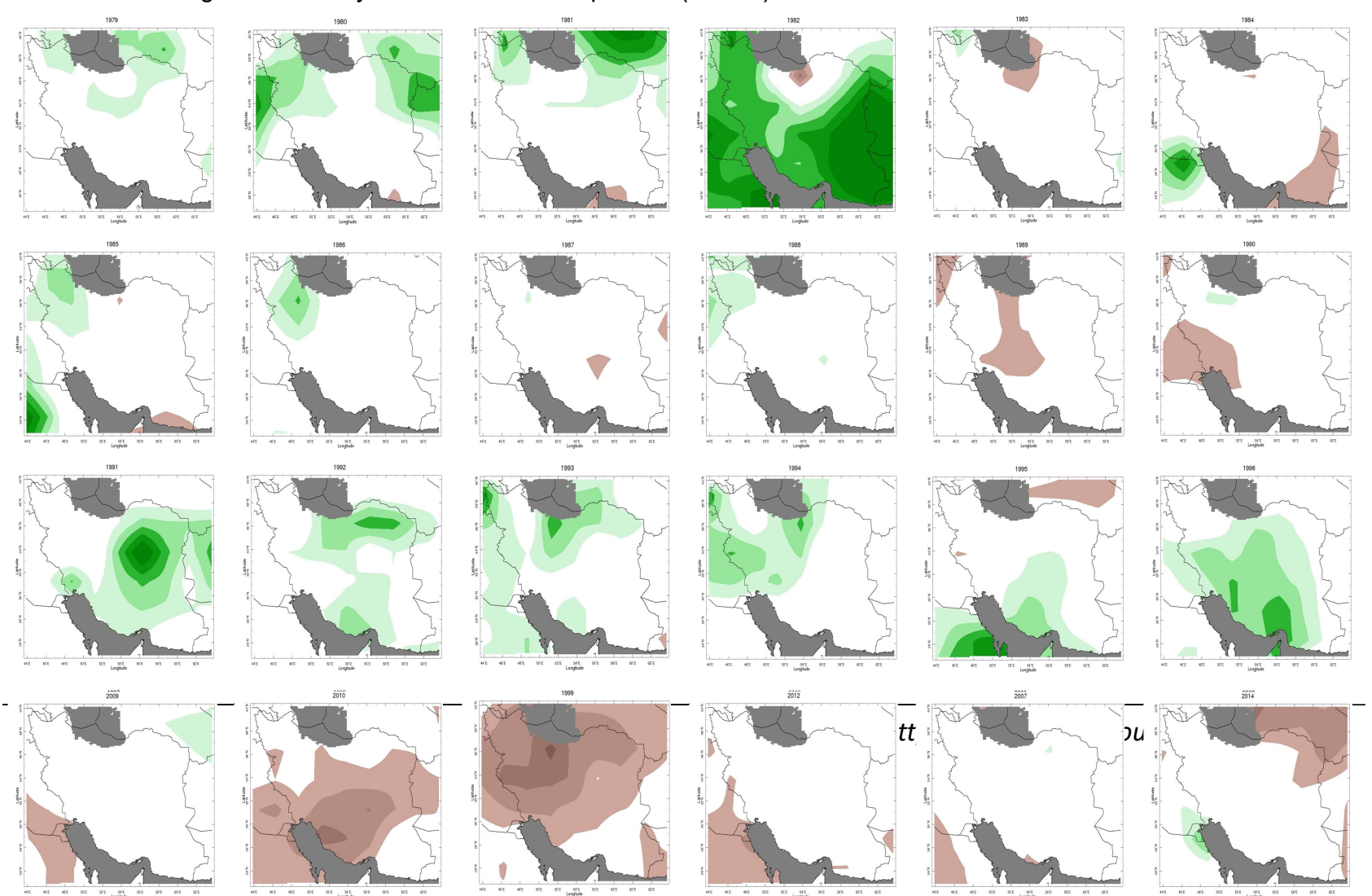




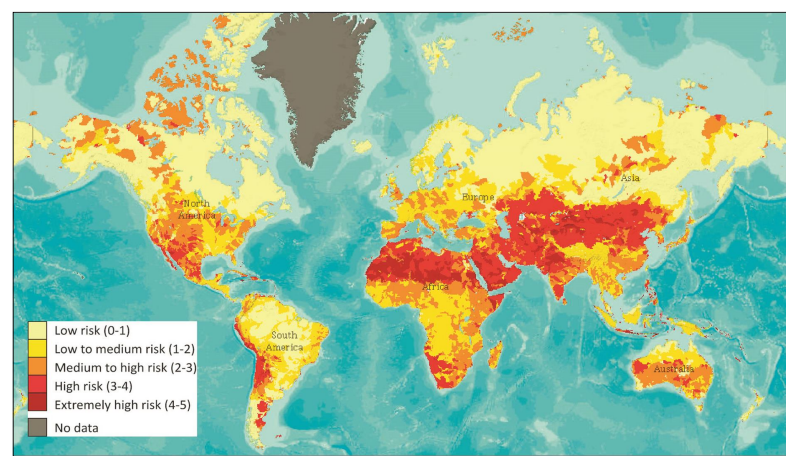

FIGURE 9: Water Risk Worldwide, Source: World Resources Institute, AQUEDUCT

The Overall Water Risk identifies areas with higher exposure to water-related risks (Figure 9) and is an aggregated measure of all selected indicators from the Physical Quantity, Quality and Regulatory Risk categories.

\subsection{Physical Risk Quantity}

Identifies areas of concern regarding water quantity that may impact short or long term water availability. Our model considered the following categories:

3.1.1 Baseline Water Stress measures the ratio of total annual water withdrawals to total available annual renewable supply, accounting for upstream consumptive use. Higher values indicate more competition among users.

3.1.2 Inter-annual Variability measures the variation in water supply from year-to-year.

3.1.3 Seasonal Variability measures variation in water supply between months of the year.

3.1.4 Flood Occurrence is a count of the number of floods recorded from 1985-2011.

3.1.5 Drought Severity estimates the average of the length times the dryness of droughts from 1901 to 2008 . Drought is defined as a continuous period where soil moisture remains below the 20th percentile, length is measured in months, and dryness is the number of percentage points below the 20th percentile.

3.1.6 Upstream Storage measures the water storage capacity available upstream of a location relative to the total water supply at that location; higher values indicate areas that should be more capable buffering variations in water supply, such as droughts or floods.

3.1.7 Groundwater stress measures the relative ratio of groundwater withdrawal to recharge rate. Values above one indicate where unsustainable groundwater consumption could affect groundwater availability and groundwaterdependent ecosystems.

\subsection{Physical Risks Quality}

Identifies areas of concern regarding water quality that may impact short or long term water availability. Our model considered the following categories:

3.2.1 Return Flow Ratio measures the percentage of available water that has been previously used and discharged upstream as waste water. Higher values indicate higher dependency on treatment plants and potentially poor water quality in areas that lack sufficient treatment infrastructure.

3.2.2 Upstream Protected Land measures the percentage of total water supply that originates from protected ecosystems. Lower values indicate areas located downstream from less protected watersheds. Water quality could, therefore, be compromised in that area.

\subsection{Regulatory Risks}

Identify areas of concern regarding uncertainty in regulatory change, as well as conflicts with the public regarding water issues.

3.3.1 Access to Water measures the percentage of population without access to improved drinking water sources. Higher values indicate areas where people have less access to safe drinking water supplies, and indicating high Regulatory Risks to those using water in an inequitable way. 
TABLE 1: II. (A) Water Risk Analysis for the IR Iran Cities with Populations Greater than 300K in the Present

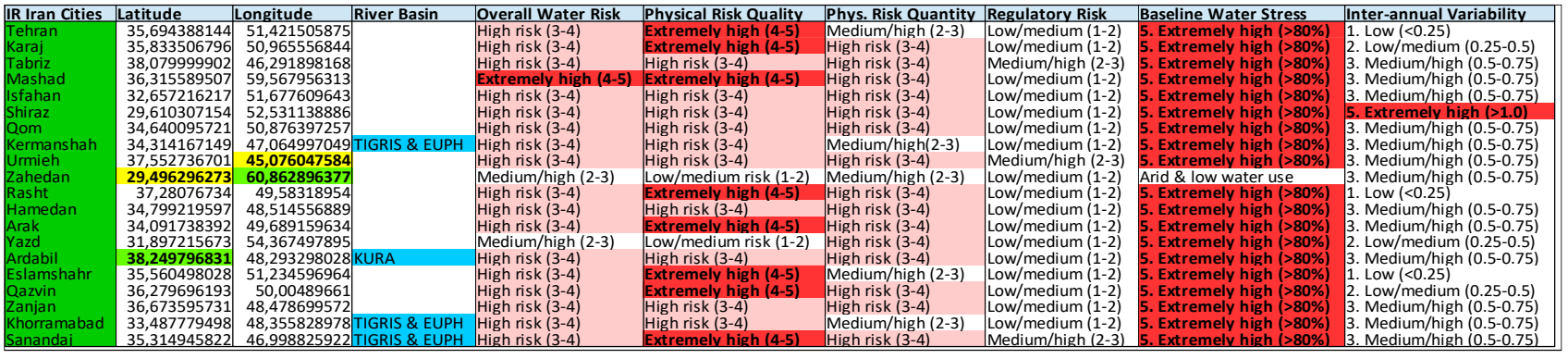

\begin{tabular}{|c|c|c|c|c|c|c|c|}
\hline CONTINUE & Seasonal Variability & Flood Occurrence & Drought Severity & Upstream Storage & Groundwater Stress & Return Flow Ratio & Upstream Protected Land \\
\hline Tehran & 2. Low/medium (0.33-0.66) & 3. Medium/high (4-9) & 3. Medium/high (30-40) & 4. $\operatorname{Low}(0.25-0.12)$ & No data & 5. Extremely high (>80\%) & 5. Extremely low $(<5 \%)$ \\
\hline Karaj & 2. Low/medium (0.33-0.66) & 3. Medium/high (4-9) & 3. Medium/high (30-40) & 4. Low $(0.25-0.12)$ & No data & 5. Extremely high (>80\%) & 5. Extremely low $(<5 \%)$ \\
\hline Tabriz & 4. High (1.0-1.33) & 4. High (10-27) & 3. Medium/high (30-40) & 3. Medium/low (0.5-0.25) & No data & 4. High $(40-80 \%)$ & 4. Low $(10-5 \%)$ \\
\hline Mashad & 2. Low/medium (0.33-0.66) & 3. Medium/high (4-9) & 4. High (40-50) & No major reservoirs & 5. Extremely high $(>20)$ & 5. Extremely high (>80\%) & 5. Extremely low $(<5 \%)$ \\
\hline Isfahan & 2. Low/medium (0.33-0.66) & 4. High (10-27) & 4. High (40-50) & 1. High (>1) & 4. High (10-20) & 4. High (40-80\%) & 4. Low $(10-5 \%)$ \\
\hline Shiraz & 3. Medium/high (0.66-1.0) & 4. High (10-27) & 4. High (40-50) & No major reservoirs & No data & 4. High (40-80\%) & 4. Low $(10-5 \%)$ \\
\hline Q.om & 3. Medium/high (0.66-1.0) & 4. High (10-27) & 4. High (40-50) & 4. Low $(0.25-0.12)$ & 4. High (10-20) & 4. High $(40-80 \%)$ & 4. Low $(10-5 \%)$ \\
\hline Kermanshah & 3. Medium/high (0.66-1.0) & 4. High (10-27) & 3. Medium/high (30-40) & 1. $\operatorname{High}(>1)$ & No data & 3. Medium/high (20-40\%) & 5. Extremely low $(<5 \%)$ \\
\hline Urmieh & 4. High $(1.0-1.33)$ & 4. High (10-27) & 3. Medium/high (30-40) & 3. Medium/low $(0.5-0.25)$ & No data & 4. High $(40-80 \%)$ & 4. $\operatorname{Low}(10-5 \%)$ \\
\hline Zahedan & 1. Low $(<0.33)$ & 4. High (10-27) & 2. Low/medium (20-30) & No major reservoirs & No data & Arid \& low water use & 5. Extremely low $(<5 \%)$ \\
\hline Rasht & 2. Low/medium (0.33-0.66) & 3. Medium/high (4-9) & 2. Low/medium (20-30) & No major reservoirs & 5. Extremely & 5. Extremely high (>80\%) & 4. Low $(10-5 \%)$ \\
\hline Hamedan & 3. Medium/high (0.66-1.0) & 4. High (10-27) & 4. High (40-50) & 4. Low $(0.25-0.12)$ & No data & 4. High $(40-80 \%)$ & 4. Low $(10-5 \%)$ \\
\hline Arak & 3. Medium/high (0.66-1.0) & 3. Medium/high (4-9) & 3. Medium/high (30-40) & No major reservoirs & No data & 4. High $(40-80 \%)$ & 5. Extremely low (<5\%) \\
\hline Yazd & 1. Low $(<0.33)$ & 4. High $(10-27)$ & 3. Medium/high (30-40) & No major reservoirs & 4. High (10-20) & Arid \& low water use & 5. Extremely low $(<5 \%)$ \\
\hline Ardabil & 3. Medium/high (0.66-1.0) & 4. High (10-27) & 2. Low/medium (20-30) & No major reservoirs & No data & 4. High (40-80\%) & 5. Extremely low $(<5 \%)$ \\
\hline Eslamshahr & 2. Low/medium (0.33-0.66) & 3. Medium/high (4-9) & 3. Medium/high (30-40) & 4. Low (0.25-0.12) & No data & 5. Extremely high (>80\%) & 5. Extremely low (<5\%) \\
\hline Qazvin & 2. Low/medium (0.33-0.66) & 3. Medium/high (4-9) & 3. Medium/high (30-40) & 4. Low $(0.25-0.12)$ & No data & 5. Extremely high (>80\%) & 5. Extremely low $(<5 \%)$ \\
\hline Zanjan & 3. Medium/high (0.66-1.0) & 4. High (10-27) & 3. Medium/high (30-40) & 2. High/medium (1-0.5) & No data & 4. High $(40-80 \%)$ & 5. Extremely low $(<5 \%)$ \\
\hline Khorramabad & 3. Medium/high (0.66-1.0) & 4. High (10-27) & 3. Medium/high $(30-40)$ & 1. High $(>1)$ & No data & 3. Medium/high (20-40\%) & 5. Extremely low $(<5 \%)$ \\
\hline Sanandaj & 3. Medium/high (0.66-1.0) & 4. High (10-27) & 3. Medium/high (30-40) & 1. High $(>1)$ & No data & 4. High $(40-80 \%)$ & 5. Extremely low $(<5 \%)$ \\
\hline
\end{tabular}

Source: Own Calculations SPSS 2015; Data: World Resources Institute, AQUEDUCT

The data collected to analyze the Overall Water Risk for the IR Iran Cities with Populations greater than 300K revealed a Medium to High Risk $(25 \%<x<75 \%)$ for Zahedan and Yazd; Extremely High Water Risk $(x<80 \%)$ for Mashad; And High Risk $(50 \%<x<80 \%)$ for the remaining cities, with an Extremely High baseline water stress $(x>$ $80 \%$ ) for all cities except Zahedan. It is of interests to note that $65 \%$ of these cities have extremely low areas of upstream protected lands $(0 \leq x<5 \%)$, and the remaining $35 \%$ of cities have a low areas of upstream protected lands $(5 \leq x<10 \%)$.

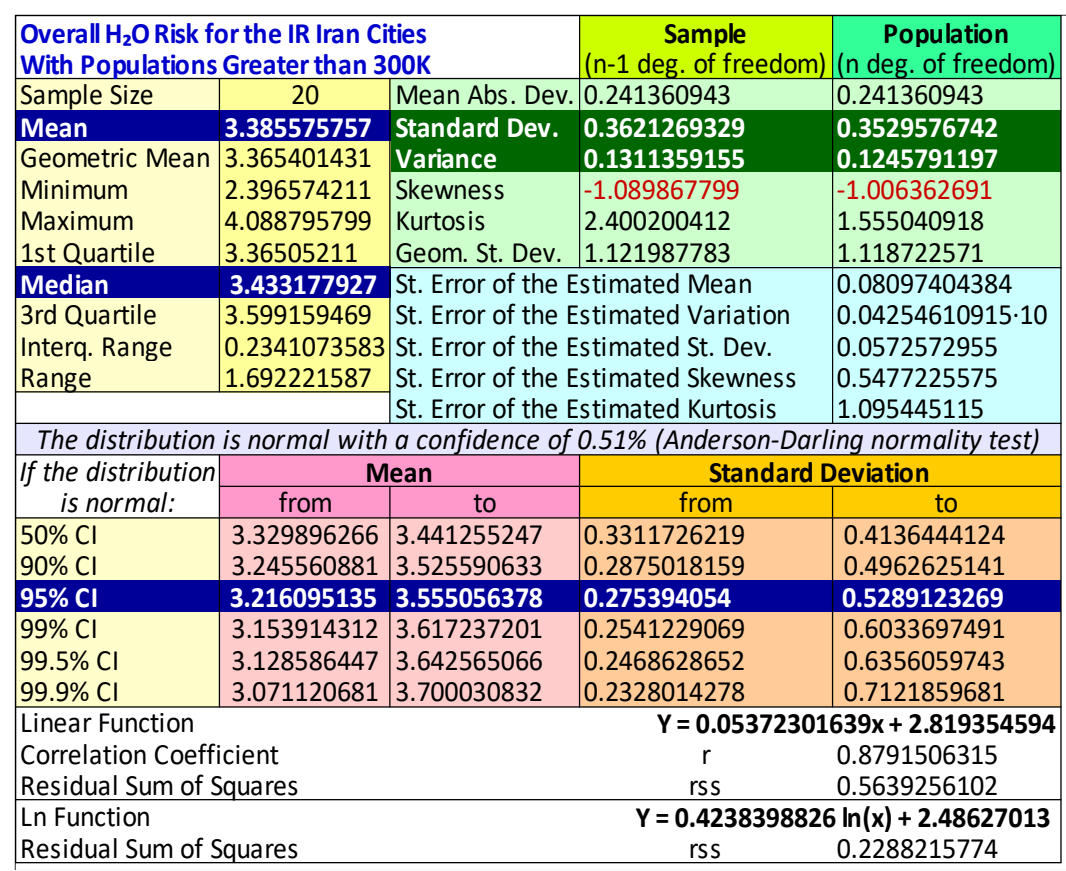

TABLE 2: Descriptive Analysis, II. (A) Current Overall Water Risk for the IRI for Cities with Populations > 300K, Source: Own Calculations SPSS 2015; Data: World Resources Institute, AQUEDUCT

TABLE 3: Pearson Corr. Coef. (R2) 
Baseline $\mathrm{H}_{2} \mathrm{O}$ Stress \& Drought Severity

Cities with Populations $300+\mathrm{K}$

\begin{tabular}{|c|c|c|c|c|c|}
\hline \multicolumn{6}{|c|}{$\begin{array}{l}\text { Pearson Correlation Coefficient for the Current Baseline } \mathrm{H}_{2} \mathrm{O} \text { Stress and } \\
\text { Drought Severity in the IRI Cities with Populations greater than } 300 \mathrm{~K}\end{array}$} \\
\hline & $\sum$ & Mean & & Dev. Squared & Value \\
\hline XValues & 51.14 & 2.557 & SSx $=$ & $\sum(X-M x)^{\wedge} 2$ & 6.9 \\
\hline YValues & 98.186 & 4.909 & SSy $=$ & $\Sigma(Y-M y)^{\wedge} 2$ & \\
\hline$X$ and $Y$ & \multicolumn{2}{|c|}{$N=20$} & $\sum(X$ & $-M x)(Y-M y)$ & -0.699 \\
\hline $\begin{array}{l}R \\
r\end{array}$ & \multicolumn{4}{|c|}{$\begin{array}{c}\Sigma((X-M y)(Y-M x)) /((S S x)(S S y))^{\wedge 1 / 2} \\
-0.699 /((6.97)(0.985))^{\wedge 1 / 2}\end{array}$} & -0.2668 \\
\hline
\end{tabular}

Source: Own Calculations SPSS 2015

The value of $R$ is -0.2668 . Although technically a negative correlation, the relationship between the variables (Baseline Water Stress and Drought Severity) is weak. The nearer the value is to zero, the weaker the relationship. The value of $\mathbf{R} 2$, the Coefficient of Determination, is $\mathbf{0 . 0 7 1 2}$. The P-Value is $\mathbf{0 . 2 5 5 1 2 6}$. The result is NOT significant at $p<0.05$.

The data collected to analyze the Overall Water Risk for the IR Iran Cities with Populations greater than $300 \mathrm{~K}$ have been converted into values on a scale from 1 to 5 , with $1=$ Low Risk $(x<25 \%), 2=$ Medium Risk $(25 \%<x<50 \%), 3=$ High Risk $(50 \%<x<75 \%), 4=$ Extremely High Risk $(75 \%<x<80 \%)$ and $5=$ Extremely High Risk ( $x>80 \%)$, with the Mean of 3.4 and $95 \% \mathrm{Cl}$ of the

Mean from 3.2 to 3.6, indicating High to Extremely High Risk (Table 2).

TABLE 4: II. (B) The Projection of Water Risk for the IR Iran Cities with Populations > 300K from 2020-2030

\begin{tabular}{|c|c|c|c|c|c|c|c|c|}
\hline $\begin{array}{l}\text { IR Cities } \\
\text { 2020-30 }\end{array}$ & Projected $\Delta \mathrm{H}_{2} \mathrm{O}$ Stress & Future $\mathrm{H}_{2} \mathrm{O}$ Stress & $\begin{array}{l}\text { Projected } \Delta \text { in } \\
\text { Seasonal Var. }\end{array}$ & $\begin{array}{l}\text { Future Seasonal } \\
\text { Variability }\end{array}$ & $\begin{array}{l}\text { Projected } \\
\Delta \mathrm{H}_{2} \mathrm{O} \text { Supply }\end{array}$ & $\begin{array}{l}\text { Future } \\
\mathrm{H}_{2} \mathrm{O} \text { Supply }\end{array}$ & $\begin{array}{l}\text { Projected } \\
\Delta \mathrm{H}_{2} \mathrm{O} \text { Demand }\end{array}$ & $\begin{array}{l}\text { Future } \\
\mathrm{H}_{2} \mathrm{O} \text { Demand }\end{array}$ \\
\hline Tehran & $1.4 x$ increase & Extremely high (>80\%) & No Change & Low-medium (0.33-0.66) & No Change & $3-10 \mathrm{~cm}$ & $1.2 x$ increase & $>30 \mathrm{~cm}$ \\
\hline Karaj & $2 x$ increase & Extremely high (>80\%) & No Change & Low-medium $(0.33-0.66)$ & $1.2 x$ decrease & $3-10 \mathrm{~cm}$ & $1.4 \mathrm{x}$ increase & $10-30 \mathrm{~cm}$ \\
\hline Tabriz & $2 x$ increase & Extremely high (>80\%) & No Change & $\operatorname{High}(1.0-1.33)$ & $1.4 x$ decrease & $3-10 \mathrm{~cm}$ & $1.4 \mathrm{x}$ increase & $10-30 c$ \\
\hline Mashad & $2 x$ increase & Extremely high (>80\%) & 1.1x decrease & Low-medium (0.33-0.66) & $1.2 x$ decrease & $1-3 \mathrm{~cm}$ & $1.7 x$ or greater increase & $10-30 \mathrm{~cm}$ \\
\hline Isfahan & $2 x$ increase & Extremely high (>80\%) & No Change & Low-medium $(0.33-0.66)$ & $1.2 x$ decrease & $1-3 \mathrm{~cm}$ & $1.4 \mathrm{x}$ increase & $10-30 \mathrm{~cm}$ \\
\hline Shiraz & $1.4 \mathrm{x}$ increase & Extremely high (>80\%) & No Change & Medium-high (0.66-1.0) & No Change & $3-10 \mathrm{~cm}$ & $1.2 x$ increase & $3-10 \mathrm{~cm}$ \\
\hline Qom & $2 x$ increase & Extremely high (>80\%) & No Change & Medium-high (0.66-1.0) & $1.4 x$ decrease & $3-10 \mathrm{~cm}$ & $1.4 \mathrm{x}$ increase & $10-30 \mathrm{~cm}$ \\
\hline Kermanshah & $2 x$ increase & Extremely high (>80\%) & No Change & Medium-high (0.66-1.0) & $1.2 x$ decrease & $3-10 \mathrm{~cm}$ & $1.4 \mathrm{x}$ increase & $10-30 \mathrm{~cm}$ \\
\hline Urmieh & $2 x$ increase & Extremely high (>80\%) & No Change & High (1.0-1.33) & $1.4 \mathrm{x}$ decrease & $3-10 \mathrm{~cm}$ & $1.4 \mathrm{x}$ increase & $10-30 \mathrm{~cm}$ \\
\hline Zahedan & $2.8 x$ or greater increase & Arid \& low water use & $1.1 x$ decrease & Low $(<0.33)$ & No Change & $1-3 \mathrm{~cm}$ & $1.7 x$ or greater increase & < $1 \mathrm{~cm}$ \\
\hline Rasht & No Change & Extremely high (>80\%) & No Change & Low-medium $(0.33-0.66)$ & No Change & $3-10 \mathrm{~cm}$ & No Change & $>30 \mathrm{~cm}$ \\
\hline Hamedan & $2 x$ increase & Extremely high (>80\%) & No Change & Medium-high (0.66-1.0) & $1.4 x$ decrease & $3-10 \mathrm{~cm}$ & $1.4 \mathrm{x}$ increase & $10-30 \mathrm{~cm}$ \\
\hline Arak & $2.8 x$ or greater increase & Extremely high $(>80 \%)$ & No Change & Medium-high (0.66-1.0) & $1.4 x$ decrease & $3-10 \mathrm{~cm}$ & $1.7 x$ or greater increase & $10-30 \mathrm{~cm}$ \\
\hline Yazd & $2 x$ increase & Extremely high (>80\%) & No Change & $\operatorname{Low}(<0.33)$ & $1.2 x$ decrease & $1-3 \mathrm{~cm}$ & $1.7 x$ or greater increase & $3-10 \mathrm{~cm}$ \\
\hline Ardabil & $1.4 \mathrm{x}$ increase & Extremely high (>80\%) & No Change & Medium-high (0.66-1.0) & $1.2 x$ decrease & $3-10 \mathrm{~cm}$ & $1.2 x$ increase & $10-30 \mathrm{~cm}$ \\
\hline Bandar Abbas & $1.4 \mathrm{x}$ increase & Extremely high (>80\%) & $1.2 \mathrm{x}$ increase & Low-medium $(0.33-0.66)$ & No Change & $3-10 \mathrm{~cm}$ & $1.4 \mathrm{x}$ increase & $3-10 \mathrm{~cm}$ \\
\hline Eslamshahr & $1.4 \mathrm{x}$ increase & Extremely high (>80\%) & No Change & Low-medium $(0.33-0.66)$ & No Change & $3-10 \mathrm{~cm}$ & $1.2 x$ increase & $>30 \mathrm{~cm}$ \\
\hline Qazvin & $2 x$ increase & Extremely high (>80\%) & No Change & Low-medium $(0.33-0.66)$ & $1.2 x$ decrease & $3-10 \mathrm{~cm}$ & $1.4 \mathrm{x}$ increase & $10-30 \mathrm{~cm}$ \\
\hline Zanjan & $2 x$ increase & Extremely high (>80\%) & No Change & Medium-high (0.66-1.0) & $1.2 x$ decrease & $3-10 \mathrm{~cm}$ & $1.4 \mathrm{x}$ increase & $10-30 \mathrm{~cm}$ \\
\hline Khorramabad & $2 x$ increase & Extremely high (>80\%) & No Change & Medium-high (0.66-1.0) & $1.2 x$ decrease & $3-10 \mathrm{~cm}$ & $1.4 \mathrm{x}$ increase & $10-30 \mathrm{~cm}$ \\
\hline Sanandaj & $2 x$ increase & ely high (>80\%) & No Change & -high (0.66-1.0) & $1.4 x$ decrease & $3-10 \mathrm{~cm}$ & $1.7 x$ or greater increase & $10-30 \mathrm{~cm}$ \\
\hline
\end{tabular}

Source: Own Calculations SPSS 2015; Data: World Resources Institute, AQUEDUCT

The data collected for the Projection of Water Risk for the IR Iran Cities with Populations greater than 300K for the period of 2020 - 2030 revealed an Extremely High Water Stress $(80 \%<x)$ for all the Iranian cities considered, with Zahedan and Arak having a 2.8 times greater projected water stress; Tehran, Shiraz, Ardabil, Bandar Abbas and Eslamshahr having 1.4 times greater projected water stress; And Rasht having no change in the projected water stress. 


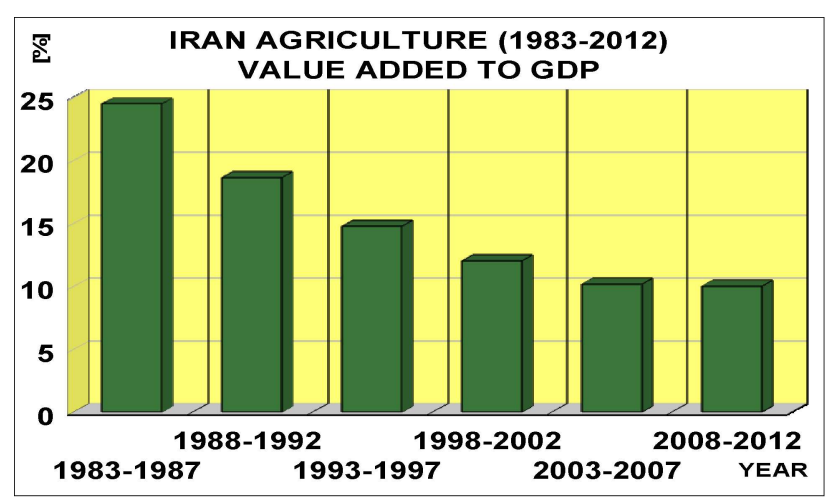

FIGURE 10: IR Iran (1983-12): Value Added to GDP from Agriculture (1983-2012) Source: Own Calculations SPSS 2015; Data: AQUASTAT

During the period of 1983 to 1987 , the IR Iran Agricultural contribution to the national GDP was about $25 \%$. Over the years, the IR Iran Agricultural contribution to the national GDP has declined dramatically. Currently, it is less than $10 \%$. Although the IR Iran total agricultural production has risen greatly, its value added to the GDP has fallen, especially due to the steep rise in the IR Iran population as well as considerable rise of value added to the GDP by other sectors of the national economy.

\section{DISCUSSION}

\subsection{Major Findings of Our Research}

Our research has determined that,

- The 1999 severe drought in the IR Iran commenced a period of unusually dry conditions, which is still ongoing (Figure 8), and likely to continue for the foreseeable future, with record high temperatures recorded this summer of 2015.

- The twenty most populous Iranian cities currently experience a medium to extremely high overall water risk, with extremely high baseline water stress that, in part, is due to the lack of upstream protected lands (Table 1), with the relationship between Baseline Water Stress and Drought Severity as weak (Table 3).

- The twenty most populous Iranian cities will likely continue to experience an extremely high water stress during the next decade (Table 4).

Although the IR Iran agricultural production has greatly risen during the past 30 years, its total contribution to the national GDP has declined. This appears to be due to the steep rise in the IR Iran population as well as considerable rise of value added to the GDP by other sectors of the national economy (Figure 10). Additionally, the Iranian agricultural sector uses over $92 \%$ of all available water resources and wastes about $70 \%$ of this water due to evaporation and lack of efficient irrigation systems (Figure 7):

\subsection{Significance of Our Research}

\subsubsection{Direct Impact on the Economy}

The results of this study show that water sector is a fundamental and basic part of any national economy. It is directly linked to the growth of other sectors, especially the agricultural sector (Boboevich et al. 2014) and its sub-sectors. The agricultural sector is an important and, arguably, one of the most important sources of long term economic growth for economies around the world (Bidabati et al. 2013 and Van Zyl et al. 1988). The economic impact of water scarcity is characterized by a disproportionately high expense input to the agricultural product output or yield (Bayad et al. 2015). For example, the Management and Planning Organization estimated the costs of the 1999 drought to be about $\$ 1.25$ Billion, of which more than 80 percent constituted damages to crops, land and livestock. According to the latest estimate, the total damages to the IR Iran national economy, resulting from the drought period of 1998 to 2001 , were over $\$ 7.5$ billion (Garshasbi 2014).

\section{- Agriculture}

With rainfall restricted to small areas of Iran in the northwest, west and the littoral zone along the Caspian Sea, rainfall water alone is unable to support the ongoing agricultural irrigation practice. Agriculture is the main water withdrawal sector. According to Iran's National Intelligence Council, irrigated systems supply water to approximately $90 \%$ of agricultural production in Iran. Despite the extensive use of irrigation, the 
overall efficiency in irrigation stands only at $33 \%$ on average. The limited water resources combined with the widespread use of inefficient and wasteful water irrigation practices result in up to three times higher water consumption than actually needed for production of crops, and are the major constraints facing agriculture in the IR Iran (Foghi 2003). Therefore, developing irrigation systems that are responsive both to natural conditions, agricultural and population needs, and preventing wasteful use of groundwater resources are critical first steps in addressing the currently critical water shortage in the Islamic Republic of Iran. This conclusion of our analysis is also supported by the former Minister of Agriculture Issa Kalantari. He has stated that water shortage is a major threat to the country, due to a careless consumption, that has depleted the IR Iran's water resources. The country's water shortage could be greatly improved through a better water management" (Khajehpour 2014).

\section{- Hydroelectric Power}

IR Iran's hydroelectric power generation is reaching a critical point amid protracted droughts which have drained water in dams to their lowest levels this summer of 2015. According to Gholamreza Khosh-Kholq, deputy head of Tavanir, Iran's power generation company, hydroelectric power normally makes up 14\% of Iran's overall electricity, but this share has now declined to less than five percent. In most of the country's nearly 50 hydroelectric plants, hydroelectric power generation has either stopped or sharply diminished, as temperatures have been rising above 40 degrees Celsius, pushing the country to the brink of widespread blackouts. Less electricity also means additional reliance on thermal plants, which produce $82 \%$ of electric power in Iran, by burning gas and oil products. The IR Iran commits one-third of its gas and more than 2 billion liters of fuel per year to its power plants. However, this method of power generation produces about $40 \%$ of the country's air pollutants. According to the International Energy Agency, energy consumption in Iran is twice more than the global average. This is most likely due to the fact that it is heavily subsidized. In 2012 , the IR Iran Government paid $\$ 82$ billion in energy subsidies, $21 \%$ of which went to electricity.

\section{- Increased food imports \& Decreased non-oil exports}

Inefficient irrigation has increased the salinity of agricultural lands, led to reduced productivity and long-term land damages, resulted in the reliance on imported and costly meats, fruits and vegetables, decreased non-oil exports and overall GDP. As water scarcity and droughts have become more frequent and common, Iran has imported more food, thus increasing its vulnerability to outside market conditions. The Islamic Republic of Iran agricultural self-sufficiency is directly dependent on the effective and sustainable long-term management of domestic water resources and technological capabilities that keep reducing the country's dependence on foreign imports.

- Non-oil exports are also affected by drought shocks in the cropping sector, since, among other factors, these variables are functions of domestic production levels (income generated) in the production sectors. The water scarcity in terms of the value added of the cropping sector causes directly and indirectly a rise of US $\$ 1.5$ billion (18.5\%) of the total non-oil imports and US $\$ 3.0$ billion (75.6\%) decrease in total non-oil exports of the IR Iran (Salami at al. 2009).

\section{- Decreased GDP \& Increased Inflation}

Changes in the value added of all three sectors, the cropping sector, livestock, manufacturing and services, sum up to a US $\$ 3.2$ billion or $4.4 \%$ change in overall GDP of the IR Iran. Furthermore, investment is reduced, especially in agriculture. Additionally, reduced supplies of food increase the consumer price index by nearly $9.6 \%$ (Salami at al. 2009).

\subsubsection{Indirect Impact on the Economy}

The social impact of water scarcity is characterized as the decrement in water resources and food security (Bayad et al. 2015).

\section{- Society}

Desertification adversely affects livelihoods and accelerates rural-urban migration. Severe drought and associated crop failures and pasture shortages contributed to a pattern of more rapid rural population decline in desertified than non-desertified provinces, and a greater rate of growth in the urban population in desertified provinces of the IR Iran (Amiraslani et al. 2011). The movement from rural areas has occurred despite a decline in rates of population growth and a reduction in the gap in fertility rates between rural and urban areas (Vahidnia 2007), suggesting that drought has contributed to this outward movement by reducing incomes and employment opportunities. In 2004 a national plan to combat desertification was ratified and this placed an emphasis on community participation. Continuing challenges include managing existing endangered areas as well as taking into account potential future problems associated with rapidly depleting 
groundwater supplies (Amiraslani et al. 2011).

- Health

The prolonged frequent droughts have led to a steady increase in frequency and intensity of dust and sand storms, which present environmental risks and affect the regional climate. Furthermore, dried up wetlands and dust storm are harmful to the Iranian economy and contribute to respiratory diseases, immunodeficiency, cancer and even depression. Furthermore, dust storms impact society by obscuring visibility and preventing free movement and travel (Reheis 2006). The severity of such storms is anticipated to increase over the coming years.

\subsection{Practical Implications and Recommendations}

\section{Proposal for the IR Iran Economic Self-sufficiency}

\section{- $\quad$ Sustainable Agriculture}

Supporting sustainable local agricultural production, including family owned small farms;

Investing in the construction of efficient and water saving delivery systems and irrigation technologies to prevent evaporation and run-off. It is estimated that $1 \%$ increase in water availability through water-saving technology results in a $1.75 \%$ reduction in the loss of crops and horticulture value added (Salami at al. 2009).

Relocating life-stocks from endangered areas to more suitable ones for grazing, based on recommendations and prudent insight of experts in the field of sustainable agricultural production and environmental protection;

Motivating farmers by offering tax refunds for amount of water and energy saved, tax-free water efficient irrigation technologies, and by government loans and hundred years free lease with options to own any government designed desertified area that they have turned into environmentally sound or agriculturally productive lands;

Adjusting agricultural price policy to induce changes in the cropping patterns and ensure the sustainability of groundwater resources.

\section{- Environmental Protection}

Protecting endangered fresh water resources and ecosystems, and establishing nationally protected reserves, especially upstream of large population centers;

Reforestation and cultivation of new vegetation cover suitable to the local environment, by providing sufficiently paid job opportunities, tax breaks and other incentives for permanent reforestation and revegetation of any government designed desertified area;

Construction of natural and artificial wind-brake barriers to reduce the severity of dust and sand storms that interfere with the natural rain cycle and prevent the discharge of water from the clouds;

Solar desalination is an emerging solution to close the water gap in the country by considering changes in policy, financing, and regional cooperation to utilize solar powered desalination of water as an alternative and additional method of efficient water management. The IR Iran has an excellent solar energy potential of about $15.3 \mathrm{kWh} / \mathrm{m} 2$ / day, which can effectively be harnessed for this purpose (Ghobadian 2015).

Moving industrial production out of large populated areas which would reduce pollution and provide priority employment and housing for workers outside of large cities.

\section{- Water and Power Conservation and Management}

Considering water conservation and sustainable water, electric power and other resources management as priority matters and national interests;

Using the clean drinking water only for drinking, recycling of water that is no longer drinkable and reusing it for other purposes, such as washing carpets, cars, streets or flushing the toilets.

Designing water efficient faucets, toilets and other and water outlets, offering tax refunds for their purchase, installation and use, and mandating their use by all agricultural and industrial enterprises and public service and government establishments, as the availability of water in large cities leads to a mistaken perception that water is plentiful, therefore, encouraging wasteful use.

Supporting the private sector in creating entry level job training and opportunities in water conservation, water desalination, and management, sustainable agriculture, environmental protection, reforestation, waste 
water cleaning and recycling, and sanitation;

Establishing higher education research grants and professional career opportunities for development and implementation of sustainable water management and agricultural production for the IR Iran;

Strengthening local governmental, media and community organizations in providing better water and health related education and services, and reducing waterborne diseases and poverty, especially in rural, low income and marginalized areas; The incidence and depth of poverty is greater in rural than urban areas (Okidegbe 2001 and Karami et al. 2013). Poor farming families in remote rural regions of the IR Iran, who were the most impacted by water scarcity and were in the greatest need, benefited the least by the government's intervention (Hayati et al. 2010).

Preventing sweet water from becoming salty and entering into the sea.

Reduction of air pollution, especially in the capital city of Tehran and other large cities. This air pollution has a direct negative effect on the health and well-being of the Iranian population and is a major contributor to the ongoing drought conditions in the IR Iran.

- $\quad$ The utilization of Space Science and Technology

Use of space technologies, including satellite remote sensing (RS) technologies and geo-spatial data have become more important recently for early warning, and can aid the Iranian Space Agency (ISA), a subsidiary of Ministry of Communication and Information Technology (MOCIT), the IR Iran Department of Environment (DOE) that is in charge of effectively using the available natural resources to ensure sustainable development, and the IR of Iran Meteorological Organization (IRIMO), that is tasked with recording and reporting vulnerabilities of different social sectors due to climate changes and drought, early warning and drought notification, and timely awareness regarding coordination of action, for a more efficient disaster management and emergency response, especially in drought and storm affected areas of the IR Iran.

Remotely sensed data provide a view of the Earth for many studies that require synoptic or periodic observations such as inventory, surveying, and monitoring in agriculture, hydrology, geology, mineralogy, and environment, and data on several key variables, including rainfall, precipitations, water storage, soil moisture and evaporation and land use, using spatial and temporal scales that are appropriate for reliable assessment. A satellite-based approach to assessment and management of drought in particular is especially important in regions where adequate water resources are lacking. Such information is often crucial in helping authorities to anticipate water and food shortages, giving them enough lead time to take preventive action.

Sustainable development requires optimal management in the environmental, economic and social dimensions. The efficient use of critical resources depends upon the availability of reliable and up-to-date information generated at the national, regional, and international levels. Earth observation from space, complemented with other applications, is an effective tool for efficient management of natural resources, for monitoring natural phenomena and for providing essential data to decision-makers to formulate policy and implement programs at the national, regional and international levels. While the potential benefits of space science and technology and its applications are well recognized, experience has shown that successful implementation and operational use of this technology is subject to the resolution of a number of major issues, including the continuous development of human resources at all levels, training of end-users, development of appropriate infrastructure and policy regulations, and allocation of necessary budgetary resources.

- National Legislation via the IR Iran Ministry of Agriculture, Energy, Health and Medical Education

Implementing long-term national policies related to the environment protection, and conservation of water, electric power and arable soil resources by the Council of Ministers;

Revising legal standards that reflect serious and firm determination in maintaining sustainable agricultural production and responsible water and electric power management.

Changing people's attitudes toward water, food and energy, and eliminating wasting, hoarding and greed. Enacting legal measures that treat water, food, electricity and any other wasting of resources as criminal offenses. This would especially apply to the still unlimited access to water resources and government subsidized energy costs, that encourage the depletion of ground water and damage to the environment, for which the user does not bear the cost nor responsibility. In the past and present times, Iranians have had little or no incentives to consider the effects of their wasted withdrawals on others or on the future water and energy levels. As groundwater is a "common" resource in the IR Iran, its use is likely to be inefficient in the absence of binding regulations (Saboohi \& Soltani 2008). 
Expanding the number and capacity of waste water treatment complexes and requiring by law that all industrial plants must build and utilize them, and all households, not connected to the city's waste water system, must have a safe septic build on their premises;

Shifting government response to water scarcity from the lax, superficial and passive crisis management to active crisis prevention, with emphasis on monitoring, early warning, effective step-by-step preparedness and readiness, and concrete action;

Forming a national emergency response and engineering corps of guardians, as part of the armed forces, who as professionals in the field would be permanently stationed in areas susceptible to natural or mancaused disasters (such as droughts, dust storms, flooding, earthquakes, fires, biochemical agents spills or any other adversity that involves mass casualties or endangers large populated areas), and tasking them with the prevention, management, reconstruction and protection of endangered or damaged areas;

Integrating water management between all levels of the government, including local, regional and national, mandating annual reviews of goals achieved, and establishing a clear chain of command and control;

\subsection{Limitations of Our Research}

\section{- The Overall Water Risk for the IR Iran Cities with Populations Greater than 300K}

We are currently unable to validate overall index scores because no data of water-related losses exist in the public domain. Data availability, specifically for major infrastructures (e.g., inter-basin transfers) and in-situ water quality and river gauge measurements, are the primary constraining factors of our model accuracy.

- Islamic Republic of Iran (1983-2012): Value Added to the IR Iran GDP from Agriculture (1983-2012)

Our data have been obtained from AQUASTAT. We were unable to cross-check and verify data from years 2007-2015, since they are not available in the public domain.

\subsection{Further Research}

Our research has been concerned with the direct economic and social impacts of water scarcity in the Islamic Republic of Iran. For a further research, it may be of importance to consider the indirect economic and social impacts of water scarcity, such as the costs associated with health care, disability, long term unemployment and forced migration of farmers from rural to large urban areas.

\section{CONCLUSION}

Climate change is a national and global concern. It has a direct impact on the social and economic prosperity of the IR Iran which is located in a geographic dry belt. Therefore, an expert scientific management of climatic changes is truly necessary to overcome the current water shortage crisis in the region. Our research indicates that since the 1999 drought, precipitation in the IR Iran has steadily declined, while environmental pollution and water consumption have increased, along with the size of the Iranian population, especially in urban areas and the capitol city of Tehran. Iranian cities are experiencing and will continue to experience a high overall water risk, with extremely high baseline water stress. The relationship between baseline water stress and drought severity has been determined as weak, indicating that other factors than drought are equal or more important contributors to water risk in the IR Iran. This water crisis is becoming especially evident during the hot summer months when water and electric energy demand has exceeded the available supply. Already this January 2015, about $74 \%$ Iranian cities were "on the verge of water crisis", and now, during the unprecedented hot summer months, the crisis is materializing, negatively impacting agricultural yield (and its quality due to salinity), generation of hydroelectric power and air quality (due to dust and sand storms). The toll on the national economy and well-being of Iranians is immeasurable. Water scarcity poses the most severe human challenge in Iran today. Mismanagement, excessive damming of rivers, inefficient and wasteful irrigation practices in the agricultural sector, pollution of the environment, unprotected land reserves especially upstream of large cities, drought and climate change have all contributed to the ongoing water crisis in the IR Iran.

\section{REFERENCE LIST}

\section{Primary Sources}

Ahmad, Y.J., Kassas, M. "Desertification: Financial Support for The Biosphere", Hodder and Stoughton, 
London, 1987.

Akbari, M. Hosseini, M., Sharifzadeh, A. "Causes, Effects and Management Mechanisms of Drought Crisisin Rural and Nomadic Communities in Southeastern Iran as Perceived by Agricultural/Rural Managers and Specialist", Journal of Human Ecology, 27(3):189-200, 2009.

Aliabadi, R. \& Bonakdar, B. “Iran's water supply challenge”, PressTV, 30 April 2015.

Amiraslani, F. and Dragovich, D. "Combating desertification in Iran over the last 50 years An overview of changing approaches", Journal of Environmental Management (Impact Factor: 3.19), January 2011; 92(1):1-13. DOI: 10.1016/j.jenvman.2010.08.012

Anon. "Strategic national plan for the desert - outlook 2025", 2008, (In Persian).

Bates, B., Kundzewicz, Z., Wu, S., Palutikof, J. "Climate Change and Water", Technical Paper, International Panel on Climate Change, (IPCC) Secretariat, Geneva, 2008.

Barlow, M., Cullen, H., Lyon, B. and Wilhelmi, O. "Drought Disaster in Asia”, Disaster Risk Management Series No. 6, The World Bank, DOI: 10.1596/978-0-8213-6332-4

Bayad, H., Ghanbari, S., Rezayi, S., . "Socio-Economical Impact Assessment of Drought on the Rural Agriculture; a Case Study of Rural District in Southern Iran", International Journal of Environmental Protection and Policy, Vol. 3, No. 2, pp. 53-56, 2015. DOI: 10.11648/j.ijepp.20150302.14

Bidabadi, F., Jansouz, P., and Pahlavani, M. "Research and Development Spending and Value Added of Agricultural Sector of Iran", International Journal of Agronomy and Plant Production, Vol., 4 (9), 20972101, 2013.

Boboevich, G., Momeni, F., Tir, N. "Exploring the Effects of Water Sector Investment in Economic Development in Iran", 3rd World Conference on Educational Technology Researches 2013, WCETR 2013, 7-9 November 2013, Antalya, Turkey, Procedia - Social and Behavioral Sciences, Volume 131, Pages 396-405, 15 May 2014.

Bozorgmehr, N. "Ecological disaster looms in Iran's dying wetlands", FT, 13 February 2015.

Dastorani, M., Kousari, M., Malekinezhad, H. and Mobin, M. "Drought Monitoring by Reconnaissance Drought Index (RDI) in Iran", Water Resource Management, 25:3485-3504, October 2011. DOI 10.1007/s11269-011-9867-1

Faramarzi, M., Abbaspour, K.C., Schulin, R., Yang, H. "Modeling blue and green water resources availability in Iran", Hydrological Processes, 23, 486-501, 2009.

Foghi, M. "The Impact of Drought on Agriculture and Fisheries in Iran", Food and Agriculture Organization of the UN, FAO Fisheries Technical Paper No. 430, Rome, 2003. ISBN 92-5-105047-3.

Garshasbi, P. "Drought conditions and management strategies in Iran", Jihad Agriculture Ministry of the IR Iran, 2014.

Ghobadian, B. and Gorjian, S. "Corrigendum to Solar desalination: A sustainable solution to water crisis in Iran", Renewable and Sustainable Energy Review, 48, 571-584, 10 June 2015.

Hayati, D., Karbalaee, F. and Yazdanpanah, M. "Coping with Drought: The Case of Poor Farmers of South Iran", Psychology and Developing Societies, 22(2) 361-383, 2010. DOI: 10.1177/097133361002200206

Hayes, M., Svoboda, M., Wilhite, D. "Understanding the complex impacts of drought: A key to enhancing drought mitigation and preparedness", Water Resource Management, 21:763-774, 2007. DOI 10.1007/s11269-006-9076-5

Karami, E., Keshavarz, M., Vanclay, F. "The social experience of drought in rural Iran”, Land Use Policy, 30(1):120-129, January 2013.

Karimkoshteh, M.H., Haghiri, M. "Water-reform strategies in Iran's agricultural sector", Perspectives on Global Development and Technology, 3 (3), 327-346, 2004.

Keramat, A., Marivani, B., and Samsami, M. "Climatic Change, Drought and Dust Crisis in Iran", World Academy of Science, Engineering and Technology, Vol. 5, 26 September 2011.

Khajeddin, S.J. "Desertification trend in Iran", Jangal-o-Marta, 74, 42-45 (in Persian), 2007.

Khajehpour, B. "Iran sinks in water crisis", Al Monitor, 3 May 2014. 
Lehane, S. "The Iranian Water Crisis", Strategic Analysis of Australia's Global Interests, 27 February 2014.

Li W., Qin Z., Tang H., Zhang H, Zhao S, Wang Q. "Modeling impact of agro-drought on grain production in China", International Journal of Disaster Risk Reduction, 7: 109-121, 2014.

Lyon, B., and Barnston, A."ENSO and the spatial extent of inter annual precipitation extremes in tropical land areas", Journal of Climate, 18, 5095-5109, 2005.

Mahdi, A., Mahdi, M., and Shafiei, M. "Factors Influencing Rural-Urban Migration from Mountainous Areas in Iran: A Case Study in West Esfahan", European Online Journal of Natural and Social Sciences, Vol. 3, No. 3, 2014.

Modarres, R., da Silva, V.P.R. "Rainfall trends in arid and semi-arid regions of Iran", Journal of Arid Environments, 70, 344-355, 2007.

NAP, National Action Programme to Combat Desertification and Mitigate the Effects of Drought of Islamic Republic of Iran. The Forest, Rangeland and Watershed Management Organization, Tehran, 2005.

Okidegbe, N. "Rural poverty: Trends and measurement", Rural development strategy background paper No. 3, The World Bank, 2001.

Qadir, M., Qureshi, A.S., Cheraghi, S.A.M. "Extent and characterization of salt affected soils in Iran and strategies for their amelioration and management", Land Degradation and Development, 19, 214-227, 2008.

Reheis, M.C. "A 16-year record of eolian dust in Southern Nevada and California, USA: controls on dust generation and accumulation", Journal of Arid Environments, 67, 487-520, 2006.

Saboohi, M. and Soltani, G. "Economic and social impacts of groundwater overdraft: The case of Iran", $15^{\text {th }}$ Economic Research Forum Annual Conference, Cairo, Egypt, 23-25 November 2008.

Salami, H., Shahnooshi, N., Thomson, K. "The economic impacts of drought on the economy of Iran: An integration of linear programming and macro-econometric modeling approaches", Ecological Economics (Impact Factor: 2.52); 68(4): 1032-1039, 02-2009. DOI: 10.1016/j.ecolecon.2008.12.003,

The World Bank. "The Northern Cities Water Supply and Sanitation Project", Document of The World Bank, Report No: 31984 - IR, Pages 29-30, April 28, 2005.

United Nations Development Programme (2006). Human Development Report 2006: Beyond ScarcityPower, Poverty and the Global Water Crisis. Basingstoke, United Kingdom: Palgrave Macmillan, 2006.

Vahidnia, F. "Case study: Fertility decline in Iran", Population and Environment, 28, pp. 259-266, 2007.

Van Zyl, J., Nel, H. and Groenewald, J. "Die bydrae van landbou tot die Suid-Afrikaanse ekonomie", Agrekon, 27(2), 1-9, 1988.

Walter, J. "World Disasters Report 2004: Focus on Community Resilience", Kumarian, Bloomfield, CT, US, 2004.

\section{Websites}

AQUASTAT http://www.fao.org/nr/water/aquastat/main/index.stm

IR Iran Ministry of Agriculture http://www.maj.ir/Portal/Home/\#

Shared Socioeconomic Pathways (SSP) Database https://secure.iiasa.ac.at/

The World Bank http://www.worldbank.org/

UN Development Programme http://hdr.undp.org/en

UN Sustainable Development https://sustainabledevelopment.un.org/index.html

World Resources Institute http://www.wri.org/our-work/project/aqueduct 